Abstract 02-S5.01 Table 1 Multivariate relations of HIV risk with social capital (components) in Mumbai and Ahmedabad

\begin{tabular}{|c|c|c|c|c|c|c|}
\hline \multirow{2}{*}{ Scale } & \multicolumn{2}{|l|}{ Casual partners } & \multicolumn{2}{|c|}{ Sex with commercial sex worker } & \multicolumn{2}{|c|}{ Condom use with CSW } \\
\hline & $\begin{array}{l}\text { Model } 1 \\
\text { OR (CI) }\end{array}$ & $\begin{array}{l}\text { Model } 2 \\
\text { AOR (CI) }\end{array}$ & $\begin{array}{l}\text { Model } 1 \\
\text { OR (CI) }\end{array}$ & $\begin{array}{l}\text { Model } 2 \\
\text { AOR (CI) }\end{array}$ & $\begin{array}{l}\text { Model } 1 \\
\text { OR (CI) }\end{array}$ & $\begin{array}{l}\text { Model } 2 \\
\text { AOR (CI) }\end{array}$ \\
\hline \multicolumn{7}{|l|}{ Mumbai } \\
\hline BO_communitaraian sense (low) & $0.53(0.32$ to 0.86$)$ & 0.78 (NS) & $0.31(0.17$ to 0.60$)$ & $0.47(0.24$ to 0.92$)$ & & \\
\hline BR_particiaption (low) & $1.97(1.19$ to 3.27$)$ & $1.90(1.13$ to 3.19$)$ & 1.60 (NS) & 1.71 (NS) & & \\
\hline LI_personal trust in services (low) & 2.33 (1.31 to 4.15$)$ & 2.39 (1.29 to 4.44$)$ & $2.45(1.08$ to 5.52$)$ & $2.84(1.23$ to 6.54$)$ & & \\
\hline $\begin{array}{l}\text { LI_reciprocal trusting relations with serv- } \\
\text { ices (low) }\end{array}$ & & 2.18 (1.11 to 4.28$)$ & $2.96(1.11$ to 7.83$)$ & $3.10(1.16$ to 8.31$)$ & & \\
\hline Married or not (ref: married) & & & & & & $0.16(0.04$ to 0.69$)$ \\
\hline No. of working days in a month (ref: low) & & & & & & $3.83(1.31$ to 11.2$)$ \\
\hline Income (ref: low) & & $1.67(1.25$ to 2.23$)$ & & 1.84 (1.26 to 2.67$)$ & & \\
\hline Income steady/fluctuating (ref: fluctuating) & & $1.93(1.08$ to 3.45$)$ & & & & \\
\hline Mode of salary receipt (daily) & & & & 1.39 (1.07 to 1.82$)$ & & \\
\hline \multicolumn{7}{|l|}{ Ahmedabad } \\
\hline B0_differences in community (low) & & & & $2.34(1.34$ to 4.11$)$ & 4.65 (2.39 to 9.02$)$ & 6.71 (3.31 to 13.6$)$ \\
\hline BO_personal trust and help (low) & $0.36(0.23$ to 0.57$)$ & $0.36(0.23$ to 0.58$)$ & $0.37(0.19$ to 0.72$)$ & $0.30(0.15$ to 0.62$)$ & $0.29(0.14$ to 0.61$)$ & $0.28(0.13$ to 0.64$)$ \\
\hline BO_generalized trust \& help (low) & 1.96 (1.34 to 2.87$)$ & $2.03(1.36$ to 3.03$)$ & $2.68(1.59$ to 4.51$)$ & 3.35 (1.88 to 5.98$)$ & 3.38 (1.83 to 6.23$)$ & 4.04 (2.14 to 7.62$)$ \\
\hline BR_generalized trust \& help (low) & & & $2.00(1.17$ to 3.42$)$ & $1.90(1.07$ to 3.37$)$ & 2.51 (1.26 to 4.99$)$ & 2.61 (1.27 to 5.37$)$ \\
\hline Living with wife or alone (ref: with wife) & & $1.77(1.45$ to 2.17$)$ & & $2.42(1.76$ to 3.33$)$ & & $2.50(1.73$ to 3.61$)$ \\
\hline Nature of job (ref: daily wage) & & $1.49(1.21$ to 1.82$)$ & & & & \\
\hline No. of working days in a month (ref: low) & & & & 2.77 (1.12 to 6.88$)$ & & \\
\hline Income (ref: low) & & & & 1.66 (1.14 to 2.43$)$ & & 1.90 (1.22 to 2.96$)$ \\
\hline Income steady or fluctuating (ref: steady) & & $1.78(1.26$ to 2.51$)$ & & $1.91(1.18$ to 3.10$)$ & & $2.31(1.29$ to 4.14$)$ \\
\hline Mode of salary receipt (daily) & & & & $68(0.48$ to 0.96$)$ & & $0.61(0.43$ to 0.88$)$ \\
\hline
\end{tabular}

The table has results from the final logistic regression models.

The low, medium and high category of social capital were treated as categorical categories and high social capital category for each component was selected as the reference category. Model 1: Social Capital Domains Only; Model 2: Social Capital Domains and Co-factors.

Only significant associations shown here.

High value of social capital measures is the reference category.

BO, Bonding social capital; BR, Bridging Social Capital; LI, Linking social capital.

capital. In Ahmedabad, bonding social capital at high levels was associated with lower risk behaviour while linking social capital at high level was associated with higher risk. On the other hand, high levels of bridging social capital and components of bridging social capital were protective of HIV risk in both the cities see Abstract O2-S5.01 table 1.

Conclusion This study was able to explore the mediating effect of social capital on migrants' HIV risk at the domain levels. Bridging kind of social capital with the host community and migrants from other states was associated with lower HIV risk behaviour. Further research should be undertaken in different epidemiological contexts to validate the findings of this study.

\section{2-S5.02 THE ASSOCIATION BETWEEN ALCOHOL USE AND HIV SEXUAL RISK BEHAVIOURS}

doi:10.1136/sextrans-2011-050109.92

${ }^{1} \mathrm{~A}$ Somji, ${ }^{2} \mathrm{~B}$ Bello, ${ }^{2} \mathrm{~S}$ Delany-Moretlwe. ${ }^{1}$ Center for Disease Dynamics, Economics \& Policy Washington, USA; ${ }^{2}$ Wits Health Institute, University of the Witwatersr and Johannesburg, South Africa

Background This study aimed to investigate the associations between alcohol use and sexual risk behaviour in migrant men and women living in Johannesburg.

Methods 1465 men and 1008 women living in six hostels and five neighbouring informal settlements respectively were surveyed. Using logistic regression, the association between five measures of alcohol use (current alcohol consumption, frequency of drinking, drunk in the past week, daily alcohol consumption, drinking habit) and five sexual risk behaviours (transactional sex, inconsistent condom use, coercive sex, multiple sexual partners and concurrency) in men and women was assessed.
Results More men than women reported current alcohol use (42\% vs $12 \%$ ). Among current drinkers, $23 \%$ of men and $29 \%$ of women reported being drunk in the past week. Consistent condom use was low in both men and women (6\%). More men (53\%) than women $(7 \%)$ reported multiple sexual partnerships. In men, frequent drinking (Adjusted OR [AOR] for upper category: 3.1, 95\% CI: $1.7 \%$ to $5.5 \%$ ) and being drunk in the past week (AOR: 3.3, 95\% CI: $1.8 \%$ to $6.0 \%$ ) were associated with coercive sex. Frequent drinking (AOR for upper category: $1.5,95 \% \mathrm{CI}: 1.1 \%$ to $2.2 \%$ ) and being drunk (AOR: $2.0,95 \%$ CI $1.4 \%$ to $3.0 \%$ ) was also associated with multiple sexual partnerships. In women, frequent drinking (AOR for upper category: $3.0,95 \%$ CI: $1.0 \%$ to $8.9 \%$ ) and being drunk in the past week (AOR: 3.4, 95\% CI: 1.3\% to 9.4\%) were experiencing coercive sex. Alcohol use did not appear to influence reported condom use. Conclusions Alcohol use was associated with several high-risk sexual behaviours in both men and women. Future HIV prevention interventions should focus on the associations between alcohol, partner violence and HIV risk.

\section{2-S5.03 SEX, DRUGS AND STRUCTURAL INTERVENTIONS: UNSTABLE HOUSING ASSOCIATED WITH INCREASED HIV RISK BEHAVIOUR IN A COHORT OF PEOPLE ON TREATMENT IN BRITISH COLUMBIA, CANADA}

doi:10.1136/sextrans-2011-050109.93

${ }^{1} \mathrm{~S}$ Parashar, ${ }^{1} \mathrm{~A}$ Palmer, ${ }^{1} \mathrm{~N}$ O'Brien, ${ }^{1} \mathrm{~K}$ Chan, ${ }^{1} \mathrm{D}$ Milan, ${ }^{1} \mathrm{H}$ Samji, ${ }^{2} \mathrm{~J}$ Montaner, ${ }^{3} \mathrm{R}$ Hogg. ${ }^{1} B C$ Centre for Excellence in HIVIAIDS, Vancouver, Canada; ${ }^{2} B C$ Centre for Excellence in HIVIAIDS, UBC, Department of Medicine, Canada; ${ }^{3} B C$ Centre for Excellence in HIVIAIDS, SFU, Faculty of Health Sciences, Canada

Background Unstable living conditions may increase risk for HIV exposure and transmission. This analysis examines housing as a 